\title{
Endometrioid Adenocarcinoma, Variant with Squamous Differentiation
}

National Cancer Institute

\section{Source}

National Cancer Institute. Endometrioid Adenocarcinoma, Variant with Squamous

Differentiation. NCI Thesaurus. Code C158610.

An endometrioid adenocarcinoma exhibiting squamous differentiation. 